\title{
Inhibition of DLC-1 gene expression by RNA interference in the colon cancer LoVo cell line
}

\author{
YUELING JIN, XIAOQIANG TIAN, YANFANG SHANG and PEILING HUANG
}

\author{
Department of Clinical Medicine, School of Clinical Medicine, Southeast University, Nanjing 210009, P.R. China
}

Received October 31, 2007; Accepted December 23, 2007

\begin{abstract}
DLC-1 (deleted in liver cancer-1) is a potential tumor suppressor gene, which is inactive in liver carcinogenesis. To observe the effects of DLC- 1 gene expression on cell proliferation and migration in the human colon cancer cell line, RNAi Lipo-recombinant of the DLC-1 gene (pGCsilDLC-1) was constructed and transduced into LoVo cells which are positive for DLC-1 gene expression. Results showed that the RNAi recombinant effectively inhibited the expression of the DLC-1 gene in LoVo cells. Additionally, our data showed decreased DLC-1 gene expression which resulted in the promotion of LoVo cell proliferation. Flow cytometry in cell cycle detection further indicated that the DLC-1 gene induced cell cycle arrest at G2/M and a cell migration assay confirmed that the knocking down of DLC-1 gene expression promotes LoVo cell migration. Our observations suggest that the DLC- 1 gene is associated with LoVo cell proliferation, migration and cell cycle distribution. DLC-1 is a potential suppressor gene in the colon cancer LoVo cell line and may play an important role in colon cancer mechanisms.
\end{abstract}

\section{Introduction}

The DLC-1 (deleted in liver cancer-1) gene, identified from a primary human hepatocellular carcinoma (HCC) by Yuan et al (1), is located on chromosome 8p21-22 and encodes a Rho GTPase-activating protein. The human DLC-1 gene was reported as a regulator of the Rho family of small GTPases. The Rho family plays an important role in the regulation of a variety of cellular processes including cell cycle progression, cytoskeletal organization, cell migration, malignant transformation and cell adhesion to the extracellular matrix (ECM) (2-4). It is clear that DLC-1 is the human homologue of rat p122 and is expressed in most human tissues. Its expression is frequently down-regulated or silenced in

Correspondence to: Professor Peiling Huang, Department of Clinical Medicine, School of Clinical Medicine, Southeast University, Nanjing 210009, P.R. China

E-mail: hpl@seu.edu.cn; huangpeilin2002@yahoo.com.cn

Key words: RNA interference, deleted in liver cancer-1 gene, proliferation, cell cycle, cell migration various types of human cancers (5). It has been reported that DLC-1 was down-regulated by promoter hypermethylation in carcinoma of the liver, colon, breast and prostate $(6,7)$. Methylation of DLC-1 is also common in hematological malignancies (8). There are many studies which have shown that the transfection of the DLC-1 gene caused significant growth inhibition and colony formation in human HCC cells and abolished tumorigenicity of non-small cell lung carcinoma cell lines in nude mice $(9,10)$. Recent studies have demonstrated that restoration of DLC-1 in breast cancer cells resulted in the inhibition of cancer migration and invasion (11). In addition, Wong et al (12) reported that DLC-1 expression reduced the migration and invasiveness of SMMC-7721 HCC cells. Since the DLC-1 gene is very important in tumor carcinogenesis, the potential for an effective therapy based on DLC-1 transfer to tumor cells appears high. However, DLC-1 has been less intensively examined in colon cancer, therefore it is necessary to investigate the possible involvement of DLC- 1 in human colon cancer cells. Thus, we constructed the RNAi Liporecombinant of the DLC-1 gene (pGCsil-DLC-1) to inhibit DLC-1 gene expression. It was transduced into LoVo cells, which are positive for DLC-1 gene expression, in order to observe the effects of DLC-1 on cell proliferation, cell migration and cell cycle distribution and to further elucidate the possible role of DLC-1 in colorectal tumor development.

\section{Materials and methods}

Colon cancer cell line. The human colon cancer LoVo cell line was obtained from the Shanghai Institute of Cell Biology, Chinese Academy of Sciences. Cells were cultured in RPMI-1640 (Sigma, St. Louis, MO, USA) and antibiotics were supplemented with $10 \%$ fetal bovine serum and $100 \mathrm{U} / \mathrm{ml}$ of penicillin and streptomycin at $37^{\circ} \mathrm{C}$ in a humidified $5 \% \mathrm{CO}_{2}$ and stored at $-20^{\circ} \mathrm{C}$.

RNA extraction and RT-PCR amplification. Total RNA extraction was performed using Trizol reagent (Invitrogen, Groningen, The Netherlands) according to the manufacturer's instructions. RNA $(5 \mu \mathrm{g})$ was used as a template in the first strand complementary DNA (cDNA) synthesis in a $20 \mu 1$ reaction volume. The reaction was incubated at $42^{\circ} \mathrm{C}$ for $60 \mathrm{~min}$, followed by heating at $99^{\circ} \mathrm{C}$ for $5 \mathrm{~min}$. All primers and amplification conditions in this study are listed in Table I (13). Single round $\beta$-actin amplification was used to demonstrate RNA integrity and RT performance. The final 
Table I. Each primer used and the PCR amplification conditions.

\begin{tabular}{lllc}
\hline Primer & \multicolumn{1}{c}{ 5'-3' Sequence } & \multicolumn{1}{c}{ PCR condition } & \multicolumn{1}{c}{$\begin{array}{c}\text { Size of amplified } \\
\text { products (bp) }\end{array}$} \\
\hline DLC-1 (RT-PCR) & GGACACCATGATCCTAACAC & 94/3 min (94/30 sec, 52/30 sec, & 262 \\
& CTCATCCTCGTCTGAATCGT & $72 / 40 \mathrm{sec}) \times 42,72 / 7 \mathrm{~min}$ & \\
B-actin (RT-PCR) & CCGTGGCCTTAGCTGTGCT & $94 / 3 \mathrm{~min}(94 / 30 \mathrm{sec}, 50 / 30 \mathrm{sec}$, & 457 \\
& TGTGCATAAAGTGTAAGTGTATAAGCA & $72 / 40 \mathrm{sec}) \times 42,72 / 7 \mathrm{~min}$ & \\
\hline
\end{tabular}

Table II. Oligonucleotide sequence of siRNA.

\begin{tabular}{|c|c|c|}
\hline Group & Sequence of siRNA nucleotides & Sites \\
\hline pGCsil-DLC-1 & 5'-GGAACTGAAGAGACGCAAT-3' & $1596-1614$ \\
\hline Control & 5'-TTCTCCGAACGTGTCACGT-3' & - \\
\hline
\end{tabular}

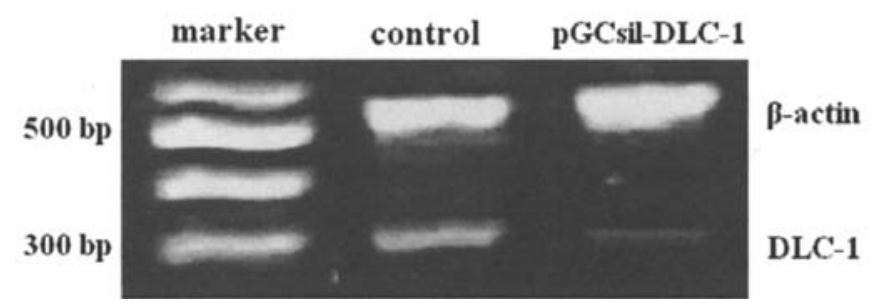

Figure 1. Inhibition of DLC-1 expression in the LoVo cell line. RT-PCR analysis was performed with total RNA extracted from the control and pGCsil-DLC-1 cells. B-actin was analysed as a positive control. The expression of mRNA was decreased in the pGCsil-DLC-1 cells. The size is $252 \mathrm{bp}$, $B$-actin is $457 \mathrm{bp}$.

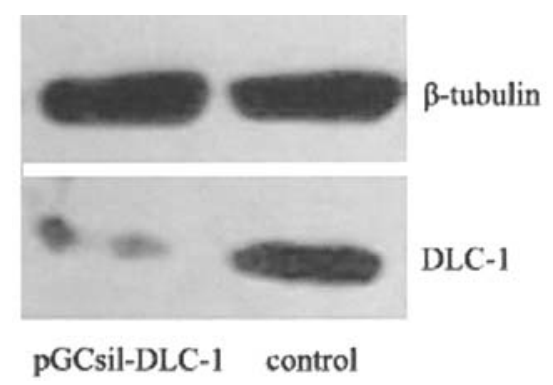

Figure 2. Western blot analysis of DLC-1 expression. Bands of $40 \mathrm{kDa}$ represent signals of $\beta$-tubulin and bands of $123 \mathrm{kDa}$ represent signals of the DLC-1 protein. Compared with the control group, a weaker expression of DLC-1 was detected in the pGCsil-DLC-1 group.

products were analyzed by electrophoresis on $2 \%$ agarose gels containing ethidium bromide.

shRNA preparation and plasmid construction. Two pairs of short hairpin RNA (shRNA) sequences were designed, one was according to the DLC- 1 sequence in the GenBank (AF035119), while the other sequence of shRNA had no homology with the human sequence and was used as a control. Each pair contained a unique 19-nt double-stranded sequence that is separated by a loop of 9-nt nucleotide sequences (ttcaagaga). The oligonucleotide sequences of siRNA that are listed in Table II, contained an EcoRI and XhoI site. After purification and restriction digestion, the oligonucleotides were ligated into plasmid pGCsi (Gene Chem Inc., China) with the polymerase III U6 promoter. DLC-1 recombinant was confirmed by sequencing and named pGCsil-DLC-1.

Transfection assay. To generate DLC-1 transfected DLC-1 cells, $3 \mu \mathrm{g}$ of plasmid DNA was transfected in $1 \times 10^{5}$ cells in a 60-mm dish using lipofectamine 2000 (Invitrogen, USA), according to the manufacturer's instructions. Selection for transfected cells was carried out in a medium containing $400 \mu \mathrm{g} / \mathrm{ml} \mathrm{G} 418$ (Geneticin; Nitrogen, USA) and the stably DLC-1 gene-transfected cells were named pGCsil-DLC-1 LoVo cells.

Western blot. pGCsil-DLC-1 LoVo and control LoVo cells $\left(10 \times 10^{6}\right)$ were respectively harvested and lysed in $60 \mu 1$ cell lysis reagent, containing $50 \mathrm{mmol} / \mathrm{l}$ Tris- $\mathrm{HCl}(\mathrm{pH} \mathrm{8.0)}$, $150 \mathrm{mmol} / 1 \mathrm{NaCl}, 100 \mu \mathrm{g} / \mathrm{ml}$ phenylmethylsulfonyl fluoride (PMSF) and 1\% Triton X-100. Equal amounts of total protein were separated by 5\% SDS-PAGE and then transferred onto polyvinylidene fluoride (PVDF). Human monoclonal antiDLC-1 (1:200; clone 3; BD Biosciences PharMingen) as primary antibodies, again incubated with bovine anti-mouse IgG (1:2500; Santa Cruz, CA) as a second antibody. B-tublin (1:3000) staining served as the internal standard for all membranes.

Soft agar colony assays. For soft agar colony assays, $3 \times 10^{3}$ LoVo cells of pGCsil-DLC-1 and control groups were respectively mixed with RPMI-1640 medium complete medium containing $0.4 \%$ agar and placed over $0.6 \%$ of basal agar in six-well culture plates. After being grown for 2-3 weeks, colonies (>30 cells) were visualized microscopically and photographed.

Cell migration assay. For migration assays, matrigel basement membrane (BD Biosciences PharMingen) matrix was coated with ECM proteins fibronectin, collagen-IV, or laminin-1. LoVo cells from pGCsil-DLC-1 and control groups $1 \times 10^{5}$ respectively were re-suspended in RPMI with $1 \%$ BSA and allowed to migrate to the undersides of the membranes for $20 \mathrm{~h}$ at $37^{\circ} \mathrm{C}$. Membranes were fixed in $4 \%$ paraformaldehyde for $10 \mathrm{~min}$. Cells remaining on the upper sides of the membranes were removed using cotton swabs. The cells 

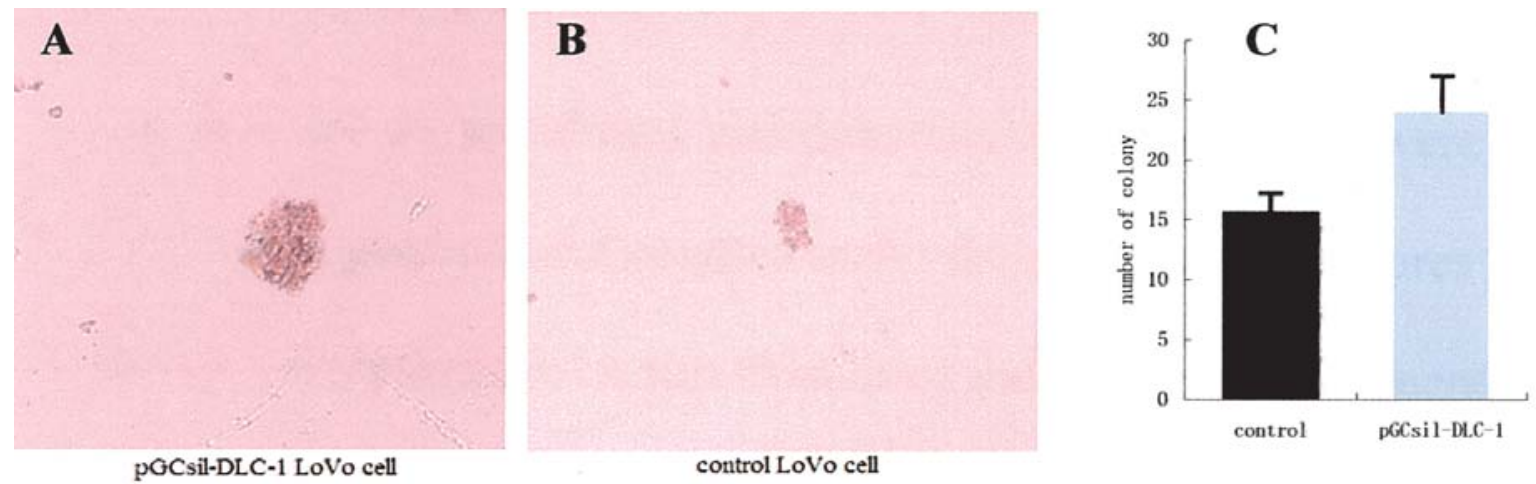

Figure 3. Inhibition of expression of DLC-1 induces cell anchorage-independent growth. Cells were grown in soft agar (0.4\%) and the colonies were visualized microscopically after 2 weeks and photographed from one representative experiment. (A and B) The size of the colonies formed by pGCsil-DLC-1 LoVo cells were significantly increased compared with the control group. (C) The number of colonies formed from three independent experiments, in the pGCsil-DLC-1 group. The mean \pm SD was $24.00 \pm 3.00$, while the control group was $15.67 \pm 1.53$.
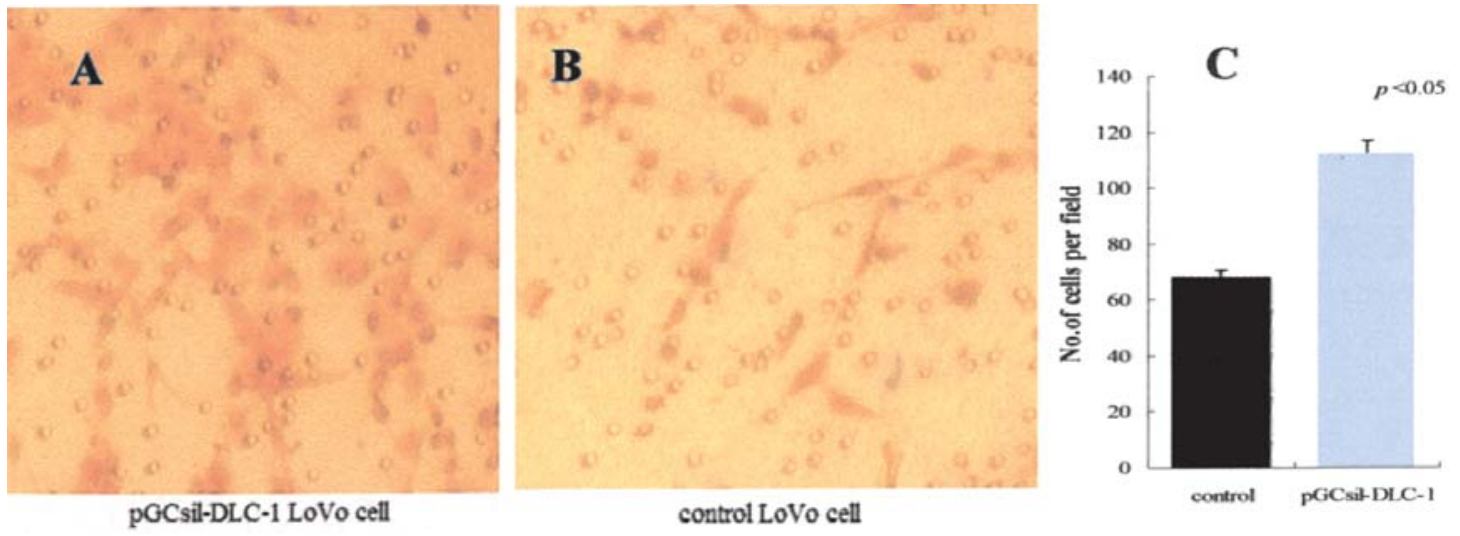

Figure 4. Detection of LoVo cell invasiveness in vitro by repression of DLC-1 expression. PGCsil-DLC-1 LoVo cells were evaluated for their ability to migrate across a matrigel-coated membrane in an invasion chamber. After incubation for $20 \mathrm{~h}$ at $37^{\circ} \mathrm{C}$, the number of cells that had migrated across the membrane was determined. Invasive cells were stained, photographed and counted under a microscope. (A and B) A representative result from three independent experiments with similar results; $(C)$ mean \pm SD of migrated cells in those three independent experiments. In the pGCsil-DLC-1 group, the mean \pm SD was $112.4 \pm 4.56$, while the control group was $68.4 \pm 2.40$. Statistical significance (t-test) was set at $\mathrm{p}<0.05$.

migrated to the underside of the membranes where they were hematoxylin and eosin stained and photographed.

Flow cytometry. LoVo cells from pGCsil-DLC-1 and control groups were respectively fixed in $70 \%$ ethanol, incubated for $5 \mathrm{~min}$ at $48^{\circ} \mathrm{C}$ with $0.1 \%$ Triton $\mathrm{X}-100$ and RNase A (100 U/ml, Sigma) and then stained with propidium iodide (50 mg/ml, Sigma). The cells were analyzed for cell cycle distribution by flow cytometry with a FACSort instrument (Becton Dickinson, Boston, MA).

\section{Results}

Inhibition of DLC-1 gene expression by shRNA expression vectors. The knock-down efficiencies of DLC-1-specific shRNAs in LoVo cells were analyzed by semiquantitive RT-PCR and Western blot, respectively. Relative DLC-1 mRNA levels were normalized by internal control $\beta$-actin and Western blot assay for DLC-1 protein expression was normalized by $\beta$-tubulin. After transfection, the mRNA and the protein expression levels of DLC-1 were reduced in the pGCsil-DLC-1 LoVo cells (Figs. 1 and 2).
DLC-1-specific shRNAs induce cell forming colonies. To evaluate the tumor suppression function of DLC-1 in colon cancer, we compared the anchorage-independent growth ability of pGCsil-DLC-1 LoVo and control LoVo cells in soft agar culture. The stably transfected pGCsil-DLC-1 LoVo cells exhibited a dramatically increasing ability to form colonies on soft agar. The number and size of colonies formed by the pGCsil-DLC- 1 LoVo cells were significantly increased compared with those of the control LoVo (Fig. 3).

DLC-1-specific shRNAs induce cell migration in vitro. To test whether DLC-1 is involved in the migration of LoVo cells, we examined the effect of the invasiveness of pGCsil-DLC-1 LoVo cells in vitro. Cells migrated through a matrigel-coated membrane during $20 \mathrm{~h}$ of incubation. Results showed that the quantity of pGCsil-DLC-1 LoVo cells that migrated into the lower compartment of the invasion chamber was markedly increased compared with the control LoVo cells. Fig. 4 displays the mean \pm standard deviation (SD) of three independent experiments, the pGCsil-DLC-1 group 112.4 \pm 4.56 and the control group $68.4 \pm 2.40$. 

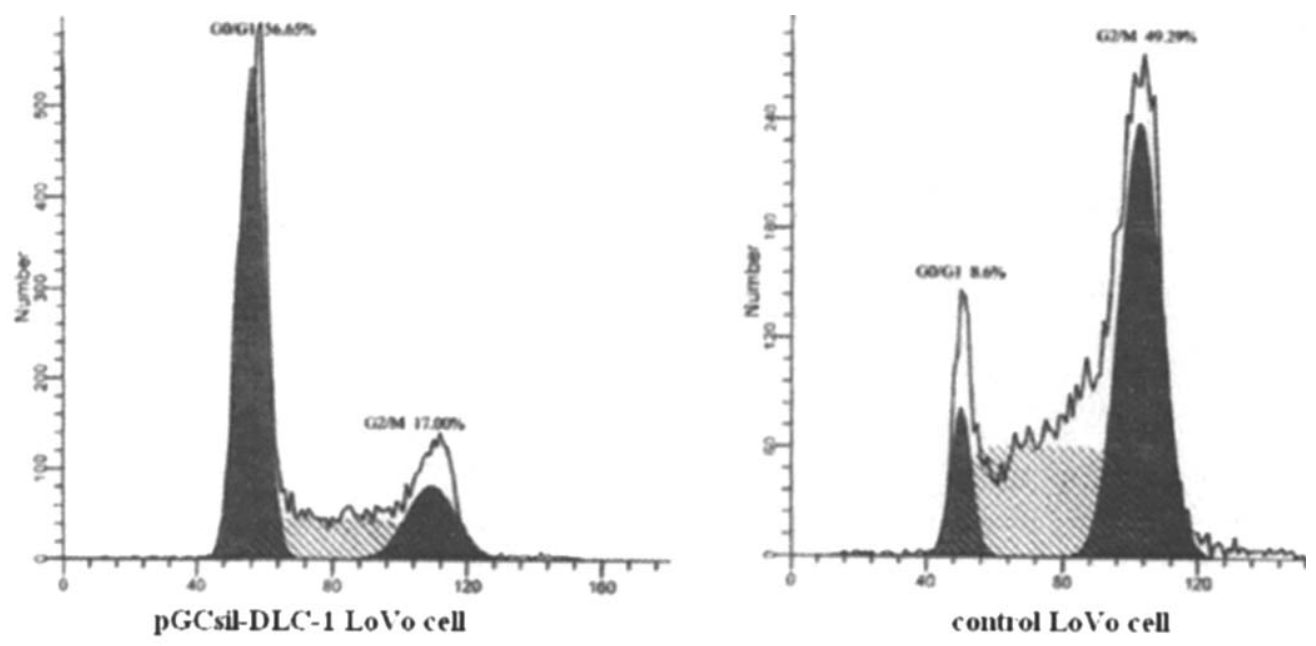

Figure 5. Effect of the DLC-1 gene on cell cycle distribution in colon cancer cell lines. LoVo cells of the pGCsil-DLC-1 and control group were detected by flow cytometry. A representative result from three independent experiments with similar results is shown. In the pGCsil-DLC-1 group, the percentage of cells in G0/G1 and G2/M were 56.65 and $17.00 \%$ respectively, while the control group, was 8.60 and $49.29 \%$, respectively.

DLC-1-specific shRNAs perturb cell cycle. We examined the possible effect of DLC-1 expression on the cell cycle by flow cytometric analysis. Results demonstrated that when compared with the control group, the population of the stably transfected pGCsil-DLC-1 LoVo cells in phases G2/M were reduced and the cells were arrested at G0/G1 (Fig. 5). These data indicated that DLC-1 gene-induced cell growth inhibition was partially attributable to cell cycle arrest.

\section{Discussion}

The candidate tumor suppressor gene DLC-1 was isolated from human hepatocellular carcinoma (HCC) by a PCRbased subtractive hybridization approach (1). Determination of the DLC-1 cDNA sequence shows that it is the human homologue of rat $\mathrm{p} 122$, which has been found to act as a Rho GTPase protein (RhoGAP ) (14). The DLC-1 gene contains a RhoGAP domain and two other functional motifs, a sterile $\alpha$ motif (SAM) domain and a StaR-related lipidtransfer (START) domain (15).

Overexpression of p122 in cultured cells induces morphological changes in adherent cells and the detachment of cells from the substratum (4). The human DLC-1 gene was reported to be a regulator of the Rho family of small GTPases, hence implicating that the DLC- 1 gene controls actin cytoskeleton organisation, membrane trafficking, gene expression, cell proliferation, malignant transformation and metastasis $(2,3)$. Further studies demonstrated that the expression of DLC-1 resulted in a marked inhibition of cell proliferation and reported that the transfer of DLC-1 into three DLC-1-negative human non-small cell lung carcinoma cell lines caused a significant inhibition in cell proliferation and a decrease in colony formation (9). DLC-1 restoration in DLC-1 negative SNU-368 human HCC cells resulted in the inhibition of cell proliferation and migration and the induction of cell morphological changes (4). In addition, the restoration of DLC-1 expression on tumorigenic breast cancer cells and hepatocellular carcinoma cells can inhibit cell invasiveness and tumorigenicity in vivo, which indicates that DLC-1 plays a tumor suppressor role $(12,16,17)$.

Based on the above, we investigated whether DLC-1 expression affects colon cancer cell growth, thus eukaryotic expression plasmid vectors of short hairpin RNA (shRNA) specific for the DLC-1 gene were designed and generated to inhibit DLC-1 expression in the LoVo cell line which highly expresses the DLC-1 gene. The data also show that lack of DLC-1 expression resulted in the promotion of cell growth and the pGCsil-DLC-1 cells exhibited a dramatically increasing ability to form colonies on soft agar compared with those of the control group, which was consistent with previous results of other research in hepatocellular carcinoma (12). We then examined whether DLC-1 had an effect on the invasive and migratory abilities of LoVo cells via transwell migration assays. Fig. 4 showed that with knocking down the DLC-1 gene expression, LoVo cells demonstrated a higher ability of migration. These findings were highly consistent with those found in cancer cell lines of different tissue types as reported by others $(10,11,16-18)$. To further substantiate how the DLC-1 gene affects LoVo cell proliferation and migration, we tested the cell cycle via FCM. After down-regulating DLC-1 gene expression, the population of LoVo cells in phases G2/M were markedly reduced and more cells arrested at the $\mathrm{G} 0 / \mathrm{G} 1$. Our results are in agreement with some recent studies, which indicated that the inhibition of cancer cell growth was via G2/M arrest and induction of apoptosis (19-23). Taken together, this strongly suggests that DLC-1 gene-inducing cell growth inhibition is partially attributable to perturb cell cycle progression.

Our results strongly suggested that DLC-1 is a tumor suppressor gene, which may be involved in the pathogenesis of colon cancer. Many studies have revealed that the DLC- 1 gene is a novel function in oncogenesis, which may provide new insight into the mechanisms underlying the carcinogenesis of colorectal cancer and may be of prognostic value for colorectal cancer. DLC-1 gene status in colorectal carcinogenesis needs further study, which should focus on 
understanding the regulation of DLC-1, as well as the detailed molecular mechanism by which DLC-1 affects cell proliferation and migration.

Generally, there are three mechanisms that lead to gene silencing, mutation, genomic deletion and promoter methylation. Mutation, as a cause of DLC-1 inactivation, is effectively ruled out because of the low rate of occurrence $(5,24)$. This implies that either genomic deletion or promoter methylation is the primary cause for altered expression or inactivation of the DLC-1 gene (2). Promoter hypermethylation is an epigenetic mechanism which may lead to the silencing of the gene expression (25). Studies have indicated that promoter hypermethylation of DLC-1 was found in HCC (26), gastric cancer (13) and prostate (7). In hematological malignancies, methylation of DLC-1 is common and has been found in $87 \%$ of non-Hodgkin's lymphomas (NHLs) and multiple myeloma tumors or tumor cell lines, though not in benign hyperplasia (8). It has also been proposed that DLC-1 methylation status in NHLs could be used as a diagnostic marker (27). This implies that promoter methylation is the primary cause for altered expression or inactivation of the DLC-1 gene (2). Thus, further study on the methylation status in colon cancer would be valuable in order to further elucidate the mechanism based on the DLC-1 gene in colon cancer carcinogenesis.

Recently, the other members of the DLC family, DLC-2 and DLC-3, have been coloned (28). DLC-2 is located on chromosome $13 \mathrm{q} 12$ which is $50 \%$ identical to DLC-1 and shares the same SAM-RhoGAP domain organization. Little is known about DLC-3 located on the X chromosome at q13 or its function. Studies have indicated that DLC-2 has an inhibitory effect on Ras-induced cellular transformation and suppression in the growth of human liver and breast tumor cells $(29,30)$. Therefore, the mechanism of the DLC as a suppressor gene, is more complicated than previously known. Currently, observations have indicated the alterations of the DLC family are in a variety of cancers, which strongly suggested that the DLC gene has potential clinical application in the prevention, early detection and therapy of cancer (31).

\section{Acknowledgements}

This study was supported by the National Natural Science Foundation of China (No. 30471937).

\section{References}

1. Yuan BZ, Miller MJ, Keck CL, Zimonjic DB, Thorgeirsson SS and Popescu NC: Cloning, characterization and chromosomal localization of a gene frequently deleted in human liver cancer (DLC-1) homologous to rat Rho GAP. Cancer Res 58: 2196-2199, 1998.

2. Park SW, Ddurkin ME, Thorgeirsson SS and Popescu NC: DNA variants of DLC-1, a candidate tumor suppressor gene in human hepatocellular carcinoma. Int J Oncol 23: 133-137, 2003.

3. Durkin ME, Yuan BZ, Thorgeirsson SS and Popescu NC: Gene structure, tissue expression and linkage mapping of the mouse DLC-1 gene (Arhgap7). Gene 288: 119-127, 2002.

4. Sekimata M, Kabuyama Y, Emori Y and Homma Y: Morphological changes and detachment of adherent cells induced by p122, a GTPaseactivating protein for Rho. J Biol Chem 274: 17757-17762, 1999.
5. Wilson PJ, McGlinn E, Marsh A, Evans T, Arnold J, Wright K, Biden K, Young J, Wainwright B, Wicking C and Chenevix-Trench G: Sequence variants of DLC1 in colorectal and ovarian tumours. Hum Mutat 15: 156-165, 2000.

6. Yuan BZ, Durkin ME and Popescu NC: Promoter hypermethylation of DLC-1, a candidate tumor suppressor gene, in several common human cancers. Cancer Genet Cytogenet 140: 113-137, 2003.

7. Guan M, Zhou Xl, Soulitzis N, Spandidos DA and Popescu NC: Aberrant methylation and deacetylation of deleted in liver cancer-1 gene in prostate cancer: Potential clinical applications. Clin Cancer Res 12: 1417-1419, 2006.

8. Song YF, Xu R, Zhang XH, Chen BB, Chen Q, Chen YM and Xie Y: High frequent promoter hypermethylation of DLC-1 gene in multiple myeloma. J Clin Pathol 59: 947-951, 2006.

9. Yuan BZ, Jefferson AM, Baldwin KT, Thorgeirsson SS, Popescu NC and Reynolds SH: DLC-1 operates as a tumor suppressor gene in human non-small cell lung carcinomas. Oncogene 23: 1405-1411, 2004.

10. Zhou X, Thorgeirsson SS and Popescu NC: Restoration of DLC-1 gene expression induces apoptosis and inhibits both cell growth and tumorigenicity in human hepatocellular carcinoma cells. Oncogene 23: 1308-1313, 2004.

11. Goodison S, Yuan J, Sloan D, Kim R, Li C, Popescu NC and Urquidi V: The RhoGAP protein DLC-1 functions as a metastasis suppressor in breast cancer cells. Cancer Res 65: 6042-6053, 2005.

12. Wong CM, Yam JW, Ching YP, Yau TO, Leung TH, Jin DY and Ng IO: Rho GTPase-activating protein deleted in liver cancer suppresses cell proliferation and invasion in hepatocellular carcinoma. Cancer Res 65: 8861-8868, 2005.

13. Kim TY, Jong HS, Song SH, Dimtchev A, Jeong SJ, Lee JW, Kim TY, Kim NK, Jung M and Bang YJ: Transcriptional silencing of the DLC-1 tumor suppressor gene by epigenetic mechanism in gastric cancer cells. Oncogene 22: 3943-3951, 2003.

14. Homma $\mathrm{Y}$ and Omori $\mathrm{Y}$ : A dual functional signal mediator showing RhoGAP and phospholipase C-d stimulating activities. EMBO J 14: 286-291, 1995.

15. Soccio RE and Breslow JL: StAR-related lipid transfer (START) proteins: Mediators of intracellular lipid metabolism. J Biol Chem 25: 22183-22186, 2003.

16. Kim TY, Lee JW, Kim HP, Jong HS, Kim TY, Jung M and Bang YJ: DLC-1, a GTPase-activating protein for Rho, is associated with cell proliferation, morphology and migration in human hepatocellular carcinoma. Biochem Biophys Res Commun 355: 72-77, 2007.

17. Yuan BZ, Zhou X, Durkin ME, Zimonjic DB, Gumundsdottir K, Eyfjord JE, Thorgeirsson SS and Popescu NC: DLC-1 gene inhibits human breast cancer cell growth and in vivo tumorigenicity. Oncogene 22: 445-450, 2003.

18. Syed V, Mukherjee K, Lyons-Weiler J, Lau KM, Mashima T, Tsuruo T and Ho SM: Identification of ATF-3, caveolin-1, DLC-1 and NM23-H2 as putative antitumorigenic, progesteroneregulated genes for ovarian cancer cells by gene profiling. Oncogene 24: 1774-1787, 2005.

19. Ullmannova V and Popescu NC: Inhibition of cell proliferation, induction of apoptosis, reactivation of DLC1, and modulation of other gene expression by dietary flavone in breast cancer cell lines. Cancer Detect Prev 31: 110-118, 2007.

20. Yang JH, Hsia TC, Kuo HM, Chao PD, Chou CC, Wei YH, et al: Inhibition of lung cancer cell growth by quercetin glucuronides via G2/M arrest and induction of apoptosis. Drug Metab Dispos 34: 296-304, 2006.

21. Lim YJ, Rhee JC, Bae YM and Chun WJ: Celecoxib attenuates 5-fluorouracil-induced apoptosis in HCT-15 and HT-29 human colon cancer cells. World J Gastroenterol 13: 1947-1952, 2007.

22. Harrison LE, Wang QM and Studzinski GP: Butyrate-induced G2/M block in caco-2 colon cancer cells is associated with decreased p34cdc2 activity. Proc Soc Exp Biol Med 222: 150-156, 1999.

23. Wang QW, Lü HL, Song CC, Liu H and Xu CG: Radiosensitivity of human colon cancer cell enhanced by immunoliposomal docetaxel. World J Gastroenterol 26: 4003-4007, 2005.

24. Zheng SL, Mychaleckyj JC, Hawkins GA, Isaacs SD, Wiley KE, Turner A, Chang BL, Kap-Herr CV, Carpten JD, Pettenati M, Bleecker ER, Walsh PC, Trent JM, Meyers DA, Isaacs WB and $\mathrm{Xu}$ JF: Evaluation of DLC1 as a prostate cancer susceptibility gene mutation screen and association study. Mutat Res 528: 45-53, 2003.

25. Jones PA and Baylin SB: The fundamental role of epigenetic events in cancer. Nat Rev Genet 3: 415-428, 2002. 
26. Wong CM, Lee JM, Ching YP, Jin DY and Ng IO: Genetic and epigenetic alterations of DLC-1 gene in hepatocellular carcinoma. Cancer Res 63: 7646-7651, 2003.

27. Shi H, Guo J, Duff DJ, Rahmatpanah F, Chitima-Matsiga R, Al-Kuhlani M, Taylor KH, Sjahputera O, Andreski M, Wooldridge JE and Caldwell CW: Discovery of novel epigenetic markers in non-Hodgkin's lymphoma. Carcinogenesis 28: 60-70, 2007.

28. Qian XL, Li G, Asmussen HK, Asnaghi L, Vass WC, Braverman R, Yamada KM, Popescu NC, Papageorge AG and Lowy DR: Oncogenic inhibition by a deleted in liver cancer gene requires cooperation between tensin binding and Rhospecific GTPase-activating protein activities. Proc Natl Acad Sci USA 104: 9012-9017, 2007.
29. Ching YP, Wong CM, Chan SF, Leung TH, Ng DC, Jin DY and Ng IO: Deleted in liver cancer (DLC) 2 encodes a RhoGAP protein with growth suppressor function and is underexpressed in hepatocellular carcinoma. J Biol Chem 278: 10824-10830, 2003.

30. Nagaraja GM and Kandpal RP: Chromosome 13q12 encoded RhoGTPase activating protein suppresses growth of breast carcinoma cells and yeast two-hybrid screen shows its interaction with several proteins. Biochem Biophys Res Commun 313: 654-666, 2004.

31. Ullmannova V and Popescu NC: Expression profile of the tumor suppressor genes DLC-1 and DLC-2 in solid tumors. Int J Oncol 29: $1127-1132,2006$. 